\title{
Assessment of Prothrombin Time, Activated Partial Thromboplastin Time And Platelets in women With Ante Partum And Post Partum Hemorrhage in Sudan, Khartoum
}

\author{
Nehal Bashir Hassan ${ }^{1}$,Dr. Amira Ahmed Khalid ${ }^{2}$ \\ ${ }^{I}$ Department Of Hematology, Faculty Of Medical Laboratory Sciences, Al-Neelain University, Khartoum, \\ Sudan. \\ ${ }^{2}$ Assistant Professor , Department Of Pathology, Faculty Of Medicine, Al-Neelain University, Khartoum, \\ Sudan.
}

\begin{abstract}
Background: Postpartum Hemorrhage is commonly defined as a blood loss of $500 \mathrm{ml}$ or more within 24 hours after birth Antepartum hemorrhage is defined as bleeding from or in to the genital tract, occurring from 24 weeks of pregnancy and prior to the birth of the baby.

Objective: The purpose of this study was toassess Prothrombin Time, Activated Partial Thromboplastin Time and Platelets count in women with ante partum and post partum hemorrhage.

Materials and Methods: One hundred samples were included in this study represent case group with ante partum and post partum. 30 samples were collected from normal pregnants, which represent control group.

Results: The results showed that the mean \pm SD of age, PT, PTT and Platelets in case group were 28.22( \pm 5.33)years, ( 15.05) ( \pm 1.87$)$ ) second, (32.70) ( \pm 4.41) secondand $258.12 X 10^{3} / \mu l( \pm 75.22)$ withP.value, (0.479), $(0.065),(0.051),(0.000)$ respectively. While the mean $\pm S D$ of age, PT, PTT and Platelets in control group were $27.33( \pm 5.53)$ years, $(14.20)( \pm 1.97)$ second, $31.54( \pm 3.06)$ second. and $338.56 \times 10^{3} / \mu l( \pm 56.29)$ respectively.

Conclusion: This study concluded that PT and APTT and Platelets count were normal in women with ante partum and post partum hemorrhage compared to normal pregnant ladies.
\end{abstract}

Keywords: Sudanese, antepartum and postpartum hemorrhage, PT, APTT, Platelets.

\section{Introduction}

Hemorrhage is the major cause of maternal mortality and morbidity worldwide. ${ }^{[1]}$

1 It is responsible for $44 \%$ of maternal. death in Africa ${ }^{[2]}$ More than 536,000 women die every year from pregnancy-related complications (malaria-related anemia, ante partum and postpartum hemorrhage). ${ }^{[3]} \mathrm{Up}$ to $20 \%$ of all maternal mortality and $15 \%$ of child death in most African settings are attributable to the lack of access to safe and adequate blood and blood products to managemalaria-associated complications, nutritional anemia, and hemorrhages .Postpartum Hemorrhage is commonly defined as a blood loss of $500 \mathrm{ml}$ or more within 24 hours after birth, is leading cause of maternal mortality in low-income countries. Most deaths resulting from PPH occur during the first 24 hours after birth: the majority of these could be avoided through the use of prophylactic uterotonics during the third stage of labour and by timely and appropriate management. ${ }^{[5]}$ deaths. ${ }^{[6]}$

Even in developed countries, for example The Netherlands, PPH causes $13 \%$ of all recorded maternal

PPH was classified into two types, primary and secondary, primary is defined as blood loss of greater than $500 \mathrm{ml}$ due to vaginal delivery and loss of $1500 \mathrm{ml}$ due to $\mathrm{C}$ section within first 24 hours of delivery. ${ }^{[7,8]}$. Secondary is defined as excessive vaginal blood loss or heavy lochial discharge occurring at least 24 hours after the end of the third stage of labor. ${ }^{[9]}$

Ante partumhemorrhage is defined as bleeding from or in to the genital tract, occurring from 24 weeks of pregnancy and prior to the birth of the baby. The most important causes of APH are placenta praevia and placental abruption.

\section{Materials And Methods}

This study a case control study, conducted in Khartoum, Sudan,Omdurman Maternity hospital, in the period from September to December 2016. 100 samples were included in this study for assessment of PT, APTT and Platelets count in women with ante partum and post partum hemorrhage. 30 samples were collected from normal pregnants which represent control group. Five $\mathrm{ml}$ of blood were collected from each subject by clean venous puncture, $3 \mathrm{ml}$ of which was placed in EDTA container for assessment of platelet count and other two ml was placed in Sodium citrate anticoagulant for measurement of PT and PTT. This study was approved by ethical committee of ministry of health, and informed consent was obtained from each participant before sample 
collection, The mean \pm SD of each parameter were determined and then compared between the case group and control group by calculating the P.value, the data were analyzed using SPSS21.

\section{Pt And Ptt Assessment}

PT was measured by delivering $0.1 \mathrm{ml}$ of patient platelet poor plasma in to containing stir in semiautomated coagulometer (COATRON-MI) diagnostic stage, $0.2 \mathrm{ml}$ was added of classified thromboplastin (CAT NO:PT200150)by automatic pipette, then pressing start at that moment. The machine recorded the measurement time at the moment which the clot was formed. APTT was measured by delivering $0.1 \mathrm{ml}$ of patient platelet poor plasma in to containing stir in semi-automated coagulometer (COATRON-MI) diagnostic stage, $0.1 \mathrm{ml}$ of the Kaolin-phospholipid solution(CAT NO: APTT202180) was added by automatic pipette and start the stopwatch simultaneously after 3 minutes added $0.1 \mathrm{ml}$ of CaCL2 then pressing start at that moment. The machine recorded the measurement time at the moment which the clot was formed.

Platelets measured by using Sysmex Kx-21N

\section{Results}

In atotal of 130 samples included in this study, 30 as control and other 100 were women with ante partum and post partum hemorrhage, as case group. Among case group there were (57) women with ante partum hemorrhage and rest of them (43) were in postpartum hemorrhage. The distribution of patients with ante partum hemorrhage according to gestational age was follow, $31(54 \%), 8(14 \%)$ and $18(32 \%)$ in first trimester, second trimester and third trimester respectively. The results showed that the mean \pm SD of age, PT, PTT and Platelets in case group with ante partum and post partum were $28.22( \pm 5.33)$ years, $(15.05( \pm 1.87))$ second , (32.70) ( \pm 4.41$)$ second and $258.12 \times 10^{3} / \mu 1( \pm 75.22)$ respectively, While the mean \pm SD of age, PT, PTT and Platelets in control group were27.33 $( \pm 5.53), 13.20( \pm 1.15), 31.00( \pm 3.06)$ and $338.56( \pm 56.29)$ respectively.

figure 1. Distribution of antepatrum among different trimesters

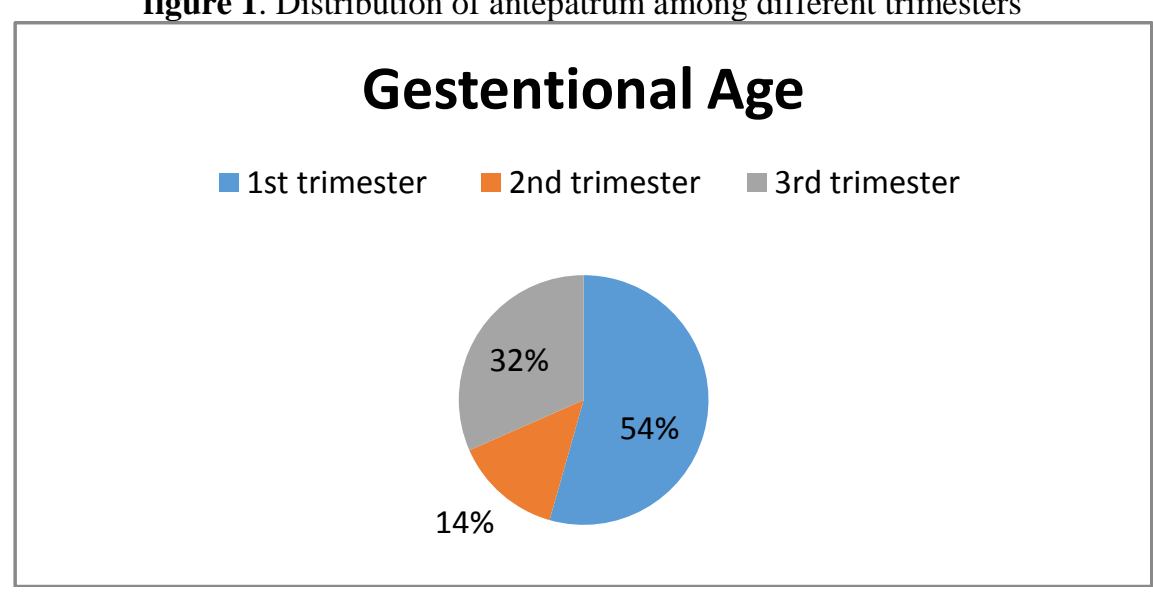

Table 1. Distribution of study groups among Prima and multi gravity

\begin{tabular}{|c|c|c|}
\hline Gravity & Case & Control \\
\hline Prima gravity + antepartum & $32(32 \%)$ & $0(0 \%)$ \\
\hline Multi gravity + antepartum & $25(25 \%)$ & $0(0 \%)$ \\
\hline Prima gravity + postpartum & $19(19 \%)$ & $0(0 \%)$ \\
\hline Multi gravity + postpartum & $24(24 \%)$ & $0(0 \%)$ \\
\hline Prima gravity & $0(0 \%)$ & $15(50 \%)$ \\
\hline Multi gravity & $0(0 \%)$ & $15(50 \%)$ \\
\hline Total & $100(100 \%)$ & $30(100 \%)$ \\
\hline
\end{tabular}

Table 2. Mean of age, PT, PTT and platelets among case and control groups

\begin{tabular}{|c|c|c|c|}
\hline & Case $( \pm$ SD) & Control $( \pm$ SD) & P. value \\
\hline Age & $28.22( \pm 5.33)$ & $27.33( \pm 5.53)$ & 0.479 \\
\hline PT (seconds) & $15.05( \pm 1.87)$ & $14.20( \pm 1.97)$ & 0.065 \\
\hline aPTT (seconds) & $32.70( \pm 4.41)$ & $31.54( \pm 3.06)$ & 0.051 \\
\hline Platelets $\left(10^{9} / \mathrm{L}\right)$ & $258.12( \pm 75.22)$ & $338.56( \pm 56.29)$ & 0.000 \\
\hline
\end{tabular}

The P.value of Age, PT, APTT and Platelets in case group is $(\mathrm{P}=0.479) .(\mathrm{P}=0.065),(0.051),(\mathrm{P}=0.000)$ respectively. 
Figure2. Mean values of PT, PTT, and platelets based on hemorrhage type

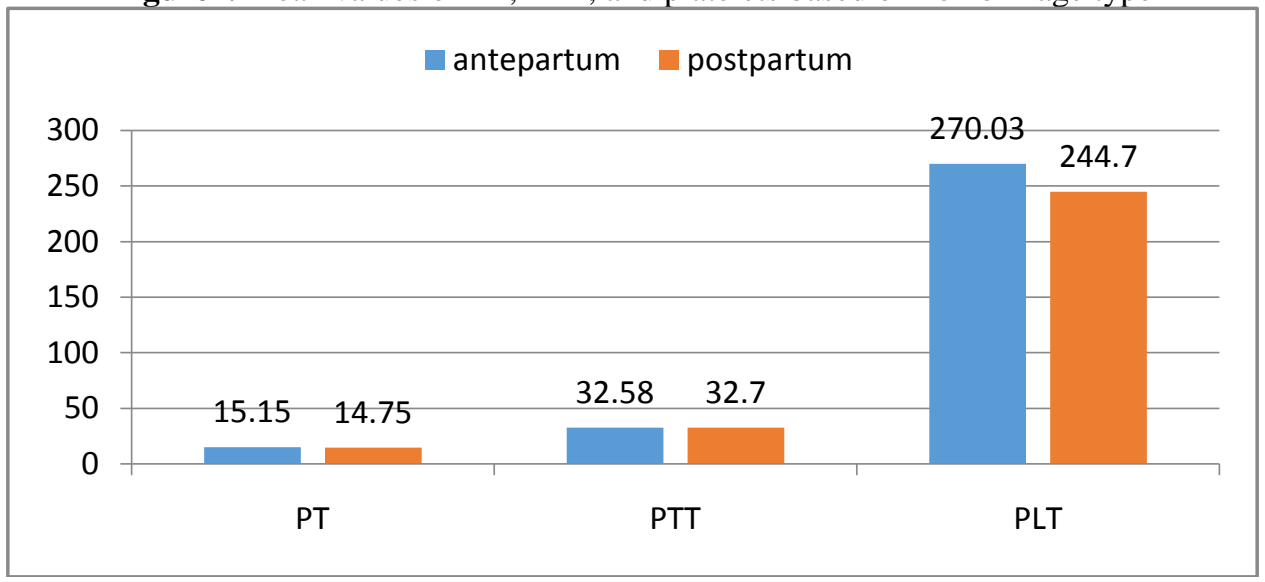

The mean of PT, PTT, and platelets in ante partum and postpartum did not show significant difference with P.value> 0.05 .

Table 3. Frequency of Abnormal Result:

\begin{tabular}{|c|c|c|}
\hline & Frequency & Percent \\
\hline Prolonged PT & 9 & $9 \%$ \\
\hline Prolonged PPT & 11 & $11 \%$ \\
\hline Decreased platelet & 13 & $61.5 \%$ \\
\hline Ante partum & 8 & $38.5 \%$ \\
\hline Post partum & 5 & $100 \%$ \\
\hline Total & 13 & . \\
\hline
\end{tabular}

Table 4. Mean of PT

\begin{tabular}{|c|c|c|c|c|}
\hline & \multicolumn{3}{|c|}{ Antepatrum } & \multirow{2}{*}{ P. value } \\
\cline { 2 - 4 } & $1^{\text {st }}$ trimester & $2^{\text {nd }}$ trimester & $3^{\text {rd }}$ trimester & 0.649 \\
\hline PT (seconds) & $24.80( \pm 3.83)$ & $23.75( \pm 4.55)$ & $23.77( \pm 4.57)$ & 0.815 \\
\hline aPTT $($ seconds) & $48.41( \pm 4.48)$ & $48.85( \pm 7.19)$ & $49.66( \pm 8.95)$ & 0.156 \\
\hline Platelets $\left(10^{9} / \mathrm{L}\right)$ & $259.12( \pm 68.35)$ & $245.37( \pm 84.32)$ & $291.72( \pm 55.00)$ & \\
\hline
\end{tabular}

, PTT and platelets in patients with ante partum in different trimesters

The mean of PT, PTT, and platelets in ante partum among different trimesters didn't show significant difference with $(\mathrm{P}=0.649),(\mathrm{P}=0.815)$ and $(\mathrm{P}=0.156)$ respectively.

\section{Discussion}

Our results showed the mean of PT and PTT and platelets count were in patients is significant. A study was done by $\mathrm{O}$ Erhabor et $\mathrm{al}^{[11]}$ went reverse with our study, in that there is significant prolongation in PT (23.17) \pm 2.708 Second and PTT (53.78) \pm 4.089 seconds in women with obstetric hemorrhage.

\section{Conclusion}

This study concluded that PT and APTT were normal in women with ante partum and post-partum hemorrhage with normal limit in Platelets count.

\section{Acknowledgement}

I dedicate this work to my mother, myself, my friends and supervisor.

\section{References}

[1]. World Health Organization, Global Burden of Maternal Hemorrhage in the year 2000.Geneva: World Health Organization; 2003. Available from:http:// www.who.int/healthinfo/statistic/bod -maternal hemorrhage.pdf.Accessed April,19 2013

[2]. Khan KS, Wojdyla D, Say L, Gulezoglu AM , Van Look PF.WHO analysis of cause of maternal death:asystemic review. Lancet.2006; 367(9516):1066-1074.

[3]. World Health Organization, Maternal Morbidity in 2005. Estimates Developed by WHO, UNICE, UNFPA, and the World Bank. Geneva: World Health Organization;2007. Available from: http// www.who.int/whosis/mme-2005.pdf.Accessed April 19,2013.

[4]. World Health Organization .the Africa Malaria Report 2003. Geneva: World Health Organization ;2003 Available from: http://apps.who.int/iris//bitstream/10665/67869/1/ WHO-CDS-MAL- 2003.1093.pdf.Accessed April 19, 2013 .

[5]. Lutomski J, Byrne B, Devane D, Greene R. Increasing trends in atonic postpartum haemorrhage in Ireland: an 11-year populationbased cohort study. BJOG. 2012 Feb. 119(3):306-14. 
[6]. Sentilhes L, Vayssière C, Deneux-Tharaux C, et al. Postpartum hemorrhage: guidelines for clinical practice from the French College of Gynaecologists and Obstetricians (CNGOF): in collaboration with the French Society of Anesthesiology and Intensive Care (SFAR). Eur J ObstetGynecolReprod Biol. 2016 Mar. 198:12-21.

[7]. Bibi S, Danish N, Fawad A, Jamil M, An audit of primary postpartum hemorrhage. J Ayub Med Coll Abbottabad 2007;19:102106. $\{$ Pub Med $\}$.

[8]. Sheikh L, Zuberi NF, Riaz R, Rizvi JH. Massive primary post partum hemorrhage: setting up standards of care. J-Pakistan Med Assoc. 2006;56(1):26\{Pub Med $\}$.

[9]. Hoveyda F, Mackenize I, Secondary post partum hemorrhage: incidence, morbidity and current management. Br J Obstet Gynaecol.2001;108(9):927-930. \{Pub Med\}.

[10]. Sheiner E, Sarid L, Levy A, Seidman DS, Hallak M. Obstetric risk factors and outcome of pregnancies complicated with early postpartum hemorrhage: a population-based study. J Matern Fetal Neonatal Med. 2005 Sep. 18(3):149-54.

[11]. Erhabor O, Isaac I, Muhammad A, Abdulrahaman Y, Ezimah A and Adias T. Some hemostatic parameters in women with obstetric hemorrhage in Sokoto, Nigeria. Int J Womens Health. 2013 Jun 14;5:285-91. 